\title{
Determination of Variator Robustness under Macro Slip Conditions for a Push Belt CVT
}

\author{
Mark van Drogen and Maaike van der Laan \\ Van Doorne's Transmissie b.v. / Bosch Group
}

Copyright @ 2003 SAE International

\begin{abstract}
Developments in clamping force control for the push belt Continuously Variable Transmission (CVT) aim at increased efficiency in combination with improved robustness. Current control strategies attempt to prevent macro slip between elements and pulleys at all times for maximum robustness. In order to search for the limiting factors in developing a new control strategy, situations where macro slip occurs have been investigated. New tribological insights show that macro slip is acceptable to a certain extent. An important failure mechanism proves to be the occurrence of adhesive wear in the contact leading to a loss in torque transfer. As a combination of normal load and slip speed, respectively clamping force and slip rate in a variator, a transition can be found from a safe wear region to an excessive/adhesive wear region. The occurrence of this transition has been verified with experiments on CVT variator level. New applications based on current understanding are found in the field of new control strategies.
\end{abstract}

\section{INTRODUCTION}

The market for belt type Continuously Variable Transmissions (CVTs) is rapidly growing. Since belt production start up at Van Doorne's Transmissie (VDT) in 1985, more than 5 million vehicles have been equipped with a push belt CVT. At this moment, 1.2 million push belt CVTs per year are used in the Japanese, North American, European and Korean markets. About 45 different vehicle models are currently available with push belt CVT.
Figure 1.1 shows the Van Doorne push belt, Figure 1.2 illustrates the working principle of the push belt variator.

To further extend the application range of its push belt, VDT is examining more severe requirements regarding transmittable power, transmission size (center distance), ratio coverage and durability. To meet those requirements, the power density of belt and pulley needs to be increased [1]. The current push belt status is nicely shown by the Nissan Murano with push belt CVT that has a ratio coverage of 5.4 and can cope with a 3.5 liter V6 $180 \mathrm{~kW} / 350 \mathrm{Nm}$ engine with torque converter, applying drive side torque levels on the belt that lie above $500 \mathrm{Nm}$ [2].

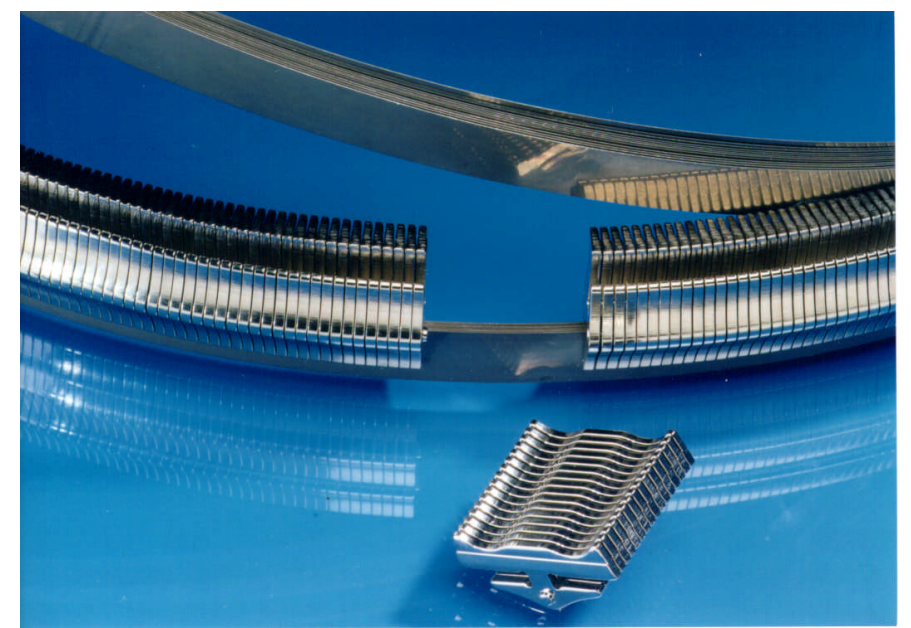

Figure 1.1 Example of a partly disassembled Van Doorne push belt with approximately 400 elements and 2 sets of 9 rings. 


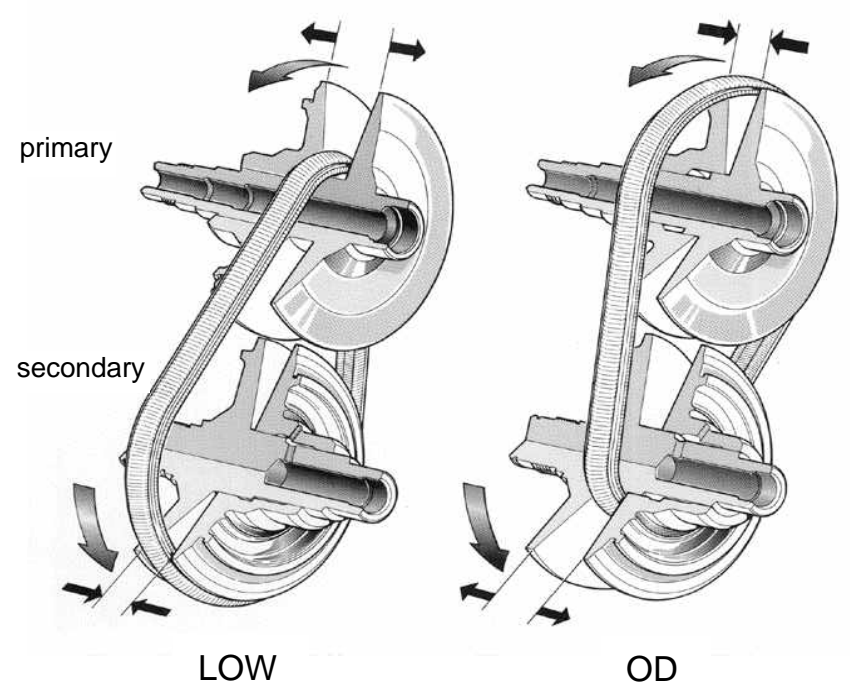

Figure 1.2 Example of a push belt variator and its working principle. In the variator, power is transmitted from the primary to the secondary pulley by means of friction between the push belt elements and the pulley sheaves. Stepless shifting between the extreme ratios LOW and OverDrive (OD) is realised by changing the axial position of the moveable pulley sheaves through changing the pulley clamping forces.

Besides increasing power density, VDT developments aim at improving the vehicle fuel consumption by improving CVT-efficiency [3]. For the state-of-the-art CVTs the fuel consumption is already at the level of the manual transmission (MT), see Figure 1.3. New technologies that will improve the fuel consumption even beyond the level of the MTs are: increasing the ratio coverage [4], reduction of actuation losses [5], application of torque fuse [3] and a decrease in variator clamping forces [6]. In [3] it is shown that a decrease in variator clamping forces (compared to the state-of-theart control strategy) can lead to a decrease in fuel consumption of $5 \%$. The investigation presented in this paper is aimed at realising this.

Lowering the variator clamping forces is beneficial for both fuel consumption, because of the decrease in power consumed by the CVT hydraulic pump, and power density, because of the decrease in push belt stresses. By lowering the clamping forces, the risk of belt slip increases, for instance in case of torque peaks, or slow or delayed hydraulic responses. One of the consequences of excessive belt slip can be severe wear in the element/pulley contact. For future improvements of the clamping force control strategy it is important to determine the failure limits for the variator system. The results of this investigation are described in this paper.

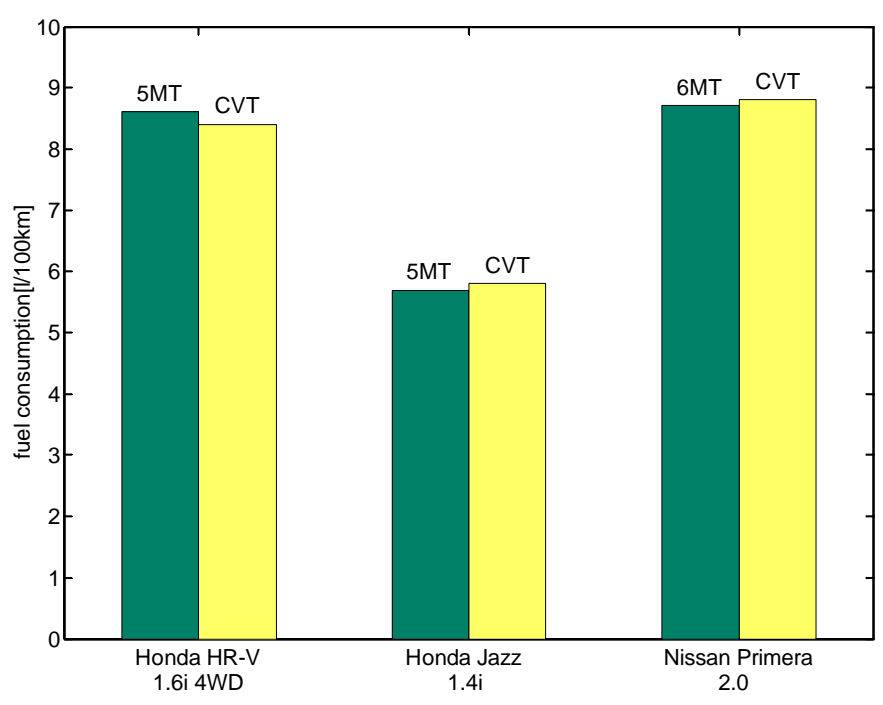

Figure 1.3 Comparison Manual Transmission (MT) versus CVT for the same drive cycle. Source: vehicle documentation.

In Chapter 2 macro slip and the variator failure mode are discussed. In Chapter 3 the measurement setup for determining the variator failure behavior is described. In Chapter 4 the measurement results are presented. Chapter 5 discusses the measurement results and their consequences for future variator control strategies. Finally the conclusions of this investigation are summarised.

\section{MACRO SLIP AND VARIATOR FAILURE MODE}

\subsection{INTRODUCTION}

Current clamping force control strategies for CVTs are designed in a way that macro slip is prevented at all times. Macro slip will occur if the applied torque is larger than the maximum transmittable torque. In a CVT design, higher clamping forces are applied in order to accomplish a certain safety margin in order to prevent the occurrence of macro slip [7].

The reasons to prevent macro slip are that, firstly, slip losses have a negative influence on the efficiency and, secondly, macro slip is often directly associated with severe belt element and pulley sheave wear. 
Severe wear in the belt-pulley interface can lead to a considerably lower torque capacity and may be regarded as a failure mode of the variator. Lower torque capacity may cause macro slip events to occur at even lower torque levels and this means a deterioration of the functional behaviour of the CVT.

Micro and macro slip are defined and explained in Section 2.2. In Section 2.3 the variator failure mode is investigated on an experimental level. Wear mechanisms and wear in relation to the contact of belt element and pulley sheave are presented in Section 2.4. In Section 2.5 failure diagrams available in literature are described.

\subsection{BELT-PULLEY MICRO/MACRO SLIP}

In the push belt CVT system, torque is transmitted by means of friction between the belt elements and the pulley sheaves. Therefore, the maximum transmittable torque is determined by the normal force and the coefficient of friction. This situation can be explained by means of a so-called slip curve [7] as is shown in Figure 2.1 .

On the horizontal axis of the slip curve, the primary or input torque $T_{p}$ is denoted and on the vertical axis the slip rate. The slip rate $s_{r}[\%]$ is defined as

$s_{r}=\frac{i_{s}-i_{0}}{i_{0}} \cdot 100 \%$,

where the speed ratio $i_{s}=n_{p} / n_{s}$ and $i_{0}$ equals the initial $i_{s}$ at the no-load condition (spin loss). At the variator test rig the secondary or output torque $T_{s}$ will be adjusted and the input torque $T_{p}$ is automatically adjusted by keeping the primary rotational speed at a constant value. It is customary at VDT that $T_{p}$ is labelled instead of $T_{s}$.

As can be seen in Figure 2.1, higher torque levels will result in an increase in slip rate which is indicative of the slip speed between belt elements and pulley sheaves. The maximum transmittable torque $T_{p, \max }$ is reached when all elements in the pulley with the lowest clamping force are needed for torque transfer. Higher torques cannot be transmitted and the result is a sharp increase in the slip rate and the slip speed between belt elements and pulley sheaves [8].

The slip rate is defined as micro slip when the slip rate level is below the slip rate level at $T=T_{p \text {,max }}$. Along the same lines, macro slip is defined as the slip rate when the slip rate level is above the slip rate level at $T=T_{p, \max }$, as shown in Figure 2.1. Excessive slip may lead to excessive wear in the contact between element and pulley. This may result in reduced torque capacity and/or modified element and pulley geometry. At the moment, the control strategy is designed to prevent the macro slip region at all times (by means of the above-mentioned safety margin) and thus the objective is that excessive slip may not occur.

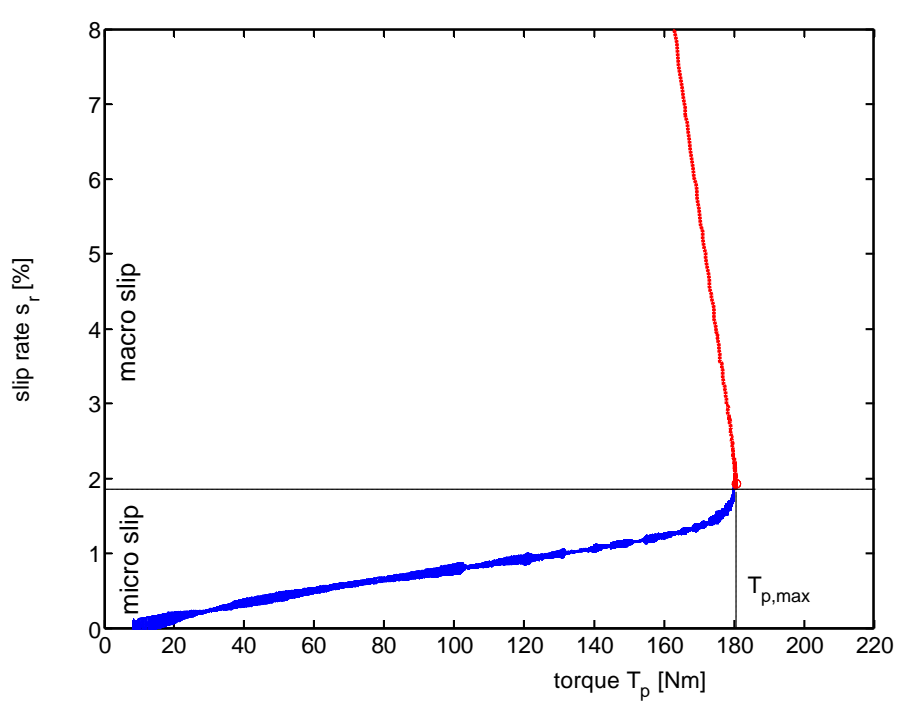

Figure 2.1 Slip curve measurement in TOP ratio.

From experience it is known that the belt does not always show excessive wear marks when it runs for a short period of time in the macro slip regime. In the test rig configuration used for the standard slip curve measurements, it is not possible to let the variator run under macro slip conditions (e.g. exactly $7 \%$ slip rate) for a longer period of time in a controlled way. When $T_{p, \max }$ is exceeded, the slip rate increases quickly in a short period of time. In the next section nevertheless, the effect of applying very short torque peaks/overshoots is investigated at this test rig configuration in order to determine the failure mode of the belt-pulley contact.

An increase of the clamping forces leads to an extension of the micro slip region. The transition to the macro slip region now occurs at higher values for $T_{p}$. In other words, the system then has a higher torque capacity. When changes in (output) torque take place at short notice (for instance torque peaks), the clamping forces need to be at such a level that $T_{p}$ stays below its critical value $T_{p}<$ $T_{p \text {,max }}$. In order to take into account the possibilities of occurrence of those torque changes/peaks, a safety factor is applied to the clamping force control strategy. Unfortunately, at a certain constant applied torque an increase of the clamping forces, and thus a safety factor, leads to a lower efficiency and a higher belt load.

In the macro slip regime it is possible to determine the coefficient of friction $\mu$ in the contact between belt 
element and pulley sheave based on the measured torque. In the macro slip regime, all elements are transferring torque and are slipping. Hence the kinetic coefficient of friction $\mu$ can be determined by

$\mu=\frac{T_{p} \cos \lambda}{2 r_{p} F_{a x, s}}$

where $T_{p}$ is the primary torque, $\lambda$ is the cone angle and $r_{p}$ represents the primary running radius. The coefficient of friction at $T_{p, \max }$ is used to characterise the torque capacity of the system [7].

\subsection{BELT-PULLEY FAILURE MODE INVESTIGATION}

In this section measurements to determine the variator failure mode are presented. It is important to know what kind of wear will be introduced during macro slip and how this will substantially affect the functionality of the variator.

Factors that may play a role in the occurrence of wear in the contact between belt element and pulley sheave are normal force, frictional force and relative motion/slip. Bearing these factors in mind, it is interesting to see if it is possible to map a region of critical parameters that will result in a condition of

1. decreased functionality and/or total failure of the beltpulley contact due to wear,

2. no decreased functionality and/or failure of the beltpulley contact due to wear.

A large number of subsequent slip curve measurements have been performed to investigate the wear and functional behaviour under macro slip conditions. The first measurements were aimed at as small as possible macro slip rate values, then the slip rates were stepwise increased to find the possible critical behaviour. The measurement sequence is presented in Figure 2.2.

The measurements were performed in TOP ratio after 40 hours of running-in in this ratio at a nominal primary torque of $140 \mathrm{Nm}$, for more information about the measurement procedure and settings see [7]. The specifications of the used variator are presented in Table 2.1

For measurements no. 1 to 10 at a slip rate of $2 \%$ (just in the macro slip regime as shown in Figure 2.1) the applied torque was quickly lowered to zero. Due to a small inertia delay, the slip rate had some overshoot to values larger than $2 \%$. No severe (adhesive) wear was observed and the torque capacity did not significantly differ i.e. ten times about $177 \mathrm{Nm}$ with a corresponding maximum coefficient of friction of 0.090 (i.e. $\mu$ at $T_{p, \max }$ ). From this result, it may be concluded that these successive slip curve measurement conditions do not lead to severe wear and a decreased torque capacity.

Table 2.1 Variator specifications (P811).

\begin{tabular}{|l|r|}
\hline Variator parameters \\
\hline \hline Center distance [mm] & 155 \\
Belt length [mm] & 649.7 \\
Element width [mm] & 24 \\
Number of rings per set & 9 \\
Ratio coverage [-] & 5.55 \\
Lubrication fluid type & 2.47 \\
\hline LOW ratio [-] & 30.0 \\
primary running radius in LOW [mm] & 74.1 \\
secondary running radius in LOW [mm] & 0.6 \\
\hline TOP ratio [-] & 66.7 \\
primary running radius in TOP [mm] & 40.0 \\
secondary running radius in TOP [mm] & 0.445 \\
\hline OD ratio [-] & 72.5 \\
primary running radius in OD [mm] & 32.3 \\
secondary running radius in OD [mm] & \\
\hline
\end{tabular}

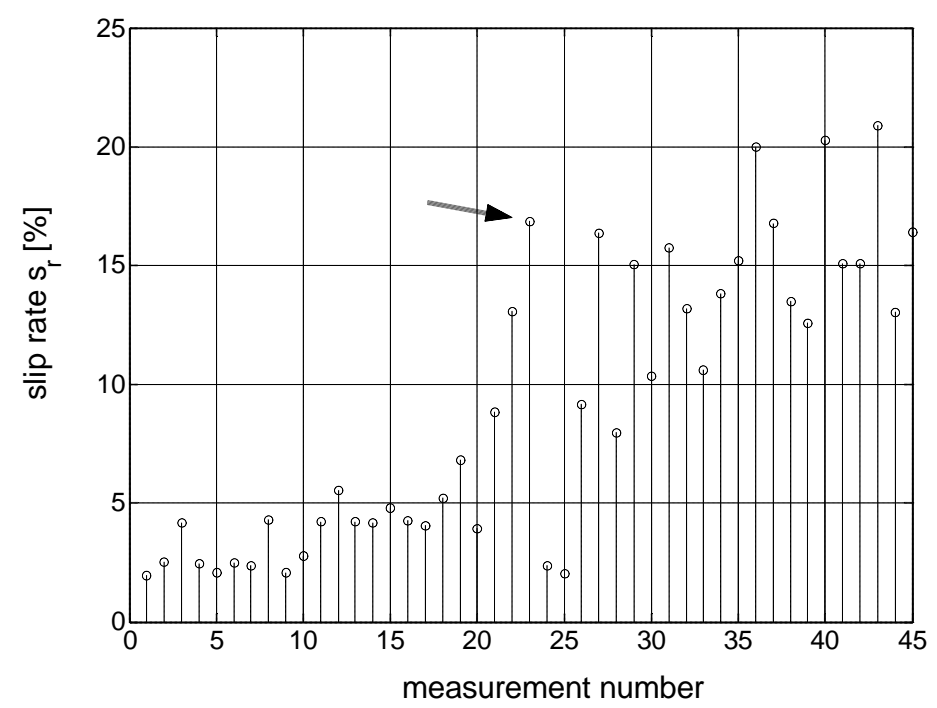

Figure 2.2 Overview diagram of slip rate $s_{r}$ values per measurement.

For the next measurements the maximum slip rate per test was increased. No severe wear (slip marks) was observed during these tests up to no.22. The next measurement no.23 showed adhesive slip marks on the elements (see Figure 2.3). From this we may conclude that at these operating conditions (in TOP ratio) the transition from a mild wear regime to a severe, adhesive wear regime lies at a value for the slip rate between $13.1 \%$ (no.22) and 16.9\% (no.23). 
This under the assumption that failure started at the maximum value for the slip rate. The corresponding friction curve, where the coefficient of friction is presented as a function the slip rate, (see Figure 2.5) shows unstable behaviour after reaching the maximum slip rate value. This is not the case for measurement no.22, as is shown in Figure 2.4. Hence it can be concluded that adhesive wear may occur at these measurement settings between $13.1 \%$ and $16.9 \%$.

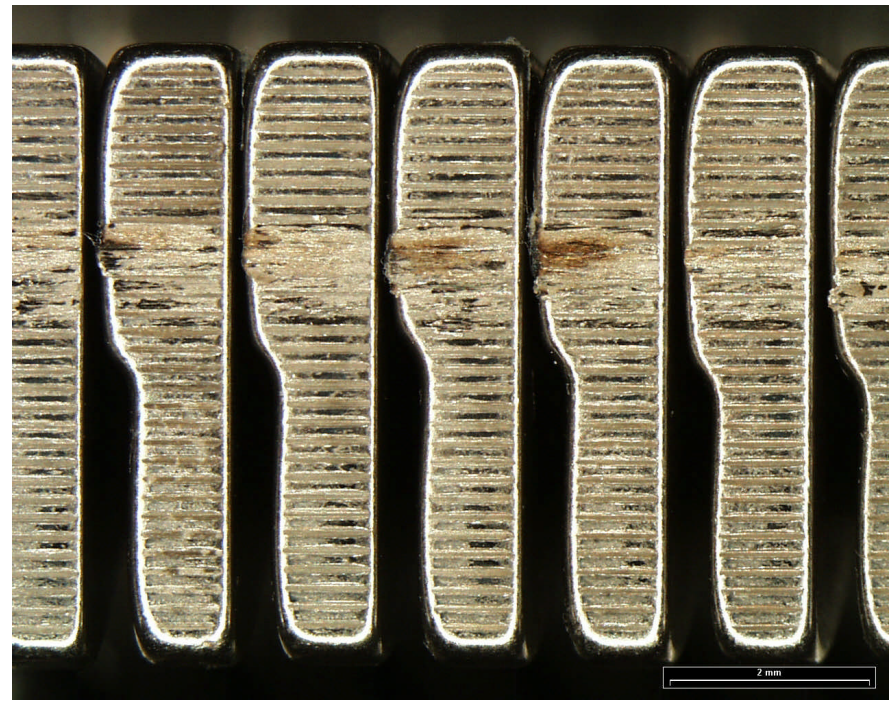

Figure 2.3 Belt elements - after 23 slip measurements.
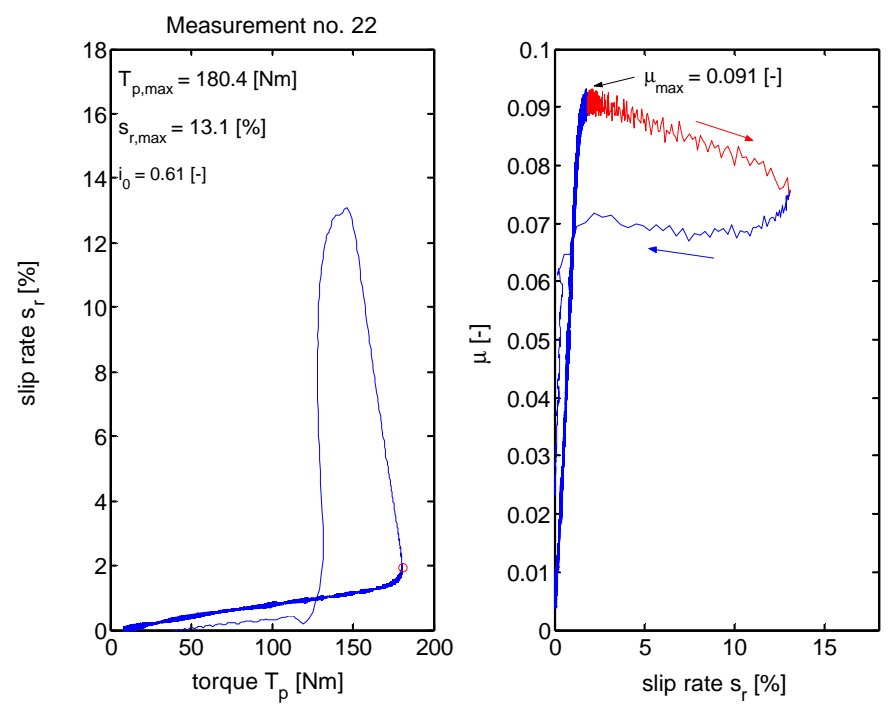

Figure 2.4 Slip curve and friction curve for measurement no.22 - no severe wear was observed after this measurement.
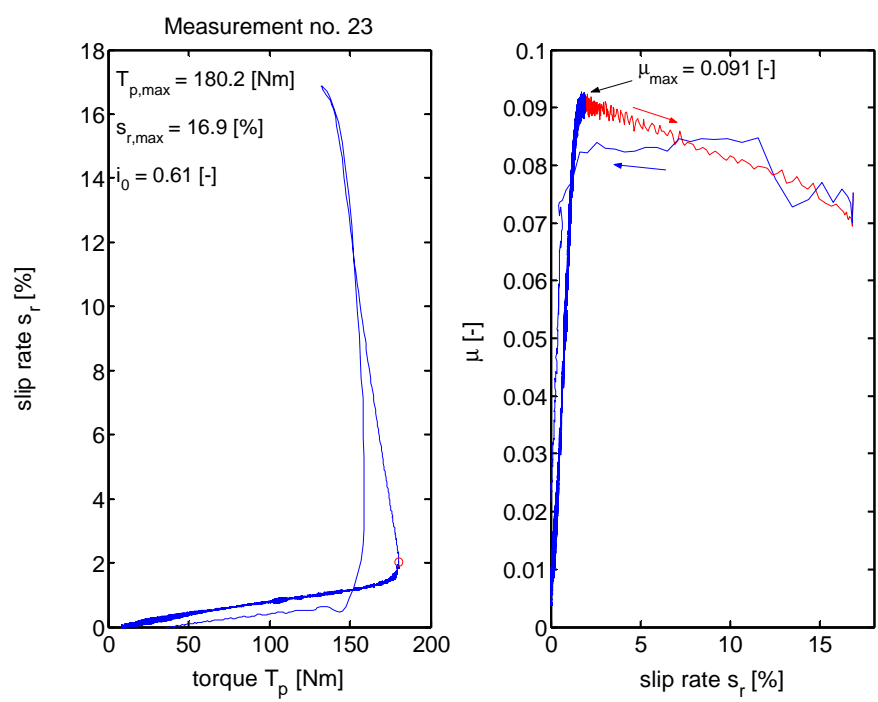

Figure 2.5 Slip curve and friction curve for measurement no.23 - severe wear was observed after this measurement.

However, no significant change in torque capacity and coefficient of friction was observed looking at the measurements no.24 and 25, where small macro slip values were applied again. From measurement no.26 on the maximum slip rate has been increased more severely in order to be sure of reaching the $16 \%$ slip or more. Slightly more adhesive wear (slip marks) on the left side of the flank was observed after measurements no.36 and 37 . Up to measurement no.40, the coefficient of friction decreases from 0.091 (first measurements) to 0.085 . After 45 slip curve measurements in total the system endured several heavy slip events and finally lowered the maximum coefficient of friction to 0.080 . The corresponding maximum torque capacity ranges from $180 \mathrm{Nm}$ in the beginning (measurement no.1) to $160 \mathrm{Nm}$ during test no.45 (11\% lower). An overview of the results for the corresponding coefficient of friction $\mu$ (calculated based on $T_{p, \max }$ ) are shown in Figure 2.7.

It may be concluded from these results that the torque capacity and hence coefficient of friction is considerably decreased after reaching the severe, adhesive wear regime with its characteristic slip marks (see Figure 2.6). The number of times and the total amount of time of each adhesive slip event determines the overall wear and also the resulting torque capacity level. Therefore, it may be concluded that the occurrence of severe, adhesive wear in a slip event must be prevented. The transition from mild to severe, adhesive wear must be regarded as a failure mode. Furthermore it can be said that under the current test conditions, the system allows quite some macro slip until this transition is reached. 


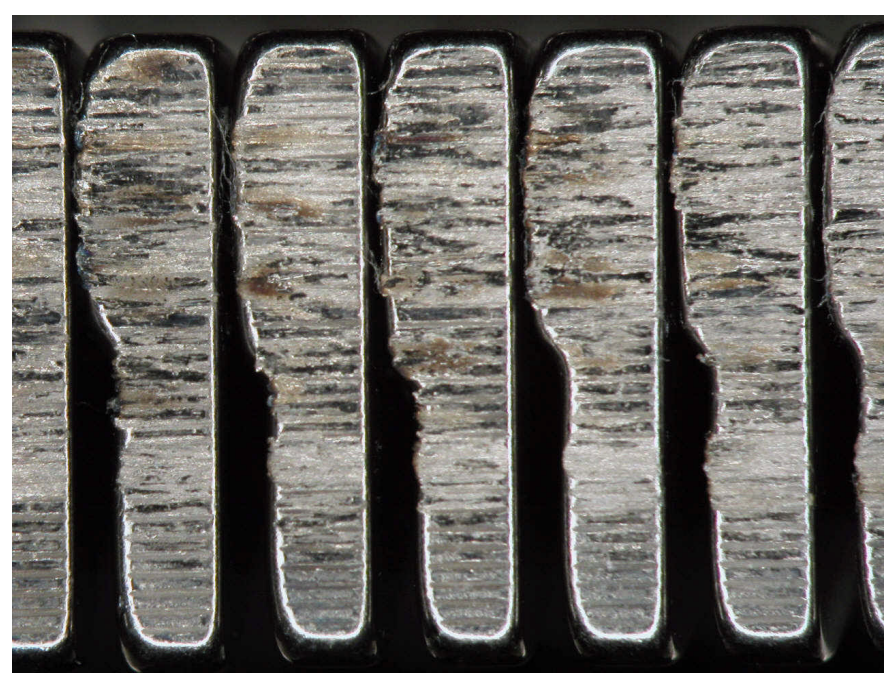

Figure 2.6 Belt elements after 45 slip measurements showing severe wear.

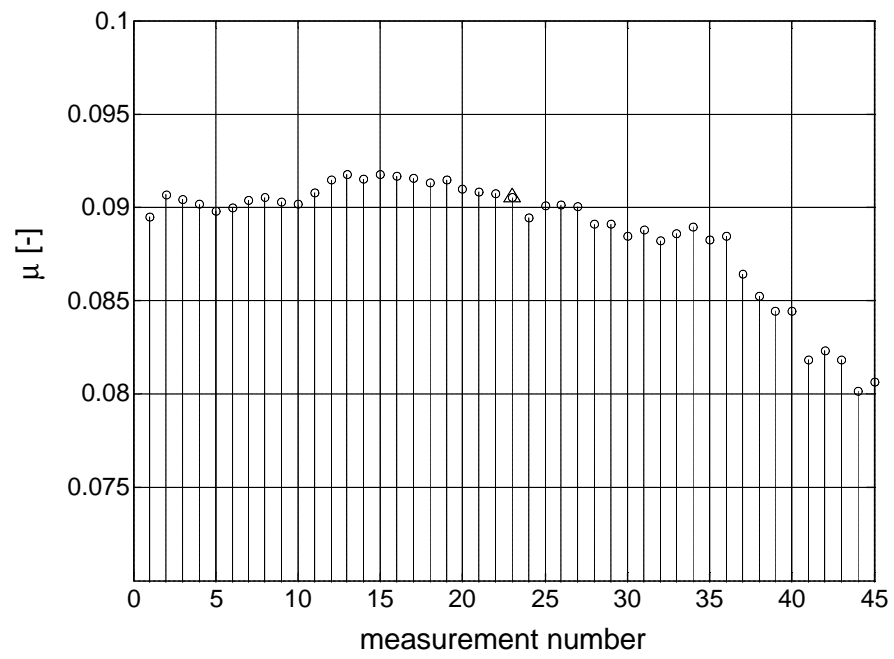

Figure 2.7 Overview diagram of coefficient of friction $\mu$ per measurement.

In the next two sections, a more fundamental approach to wear and transitions/failure is taken in order to understand the phenomena described above.

\subsection{WEAR}

\subsubsection{Wear Theory}

In general it is possible to distinguish several mechanisms that lead to wear of an engineering component in a lubricated contact. These wear mechanisms are [9]:

1. tribochemical wear

2. abrasive wear

3. fatigue

4. adhesive wear
In lubricated contacts, such as the element/pulley contact, lubrication regimes (according to the Stribeck curve) have to be taken into account. Depending on the level of separation of the contacting surfaces by the fluid, it is possible to distinguish the well-known areas: boundary, mixed and (elasto) hydrodynamic lubrication, denoted as $B L, M L$ and $E H L$ respectively $[10,11]$.

In EHL the only possible wear mechanism is fatigue. In $\mathrm{BL}$ (all of) and ML (part of) the load is carried by the roughness asperities of the contacting bodies. The asperities make contact but there is no metal-metal contact due to boundary layers formed at the interface by additives in the lubricant. Now shearing takes place in those boundary layers. If the hardness of both materials are of the same order of magnitude, thus excluding two body abrasive wear, three body abrasive, fatigue and mild chemical wear may take place. Under certain operating conditions boundary layers will not hold up due to thermal and/or mechanical means and metal-metal contact occurs, hence this may give rise to adhesive wear.

\section{Tribochemical Wear}

Under conditions of boundary lubrication (and partly mixed lubrication) asperities come in close proximity and the lubricant viscosity is relatively unimportant. The physical and chemical interactions of the lubricant with the solid surfaces control friction and wear. Additives are often used to provide the desirable wear and frictional properties and interaction with the interface.

The most obvious mechanism by which friction increases the rate of chemical reaction is frictional heat produced at contacting asperities. Tribochemical wear is the mildest form of wear. If the material removal is purely tribochemical, no microfracture or plastic deformation takes place [12].

\section{Abrasive Wear}

Abrasive wear occurs when asperities of a rough hard surface or hard particles slide on a softer surface and damage the interface by plastic deformation or fracture. The general rule of thumb is that if one surface is more than $20 \%$ harder than the other, asperities on the harder surface will plough through the softer surface $\left(H_{1}>1.2\right.$ $H_{2}$ ) [13]. This type of abrasive wear is called two body abrasion. Another type of two body abrasion occurs if for example work hardened debris is embedded in the soft surface and hence leads to hard asperities. Three body abrasive wear may occur if these particles (and particles generated elsewhere in the system) are able to move in the contact area and are not embedded at a fixed position. 


\section{Fatigue}

Surface fatigue takes place due to repeated sliding. The repeated loading and unloading cycles lead to the formation of surface cracks. After an incubation period and a critical number of cycles the formation of large fragments will occur. These lead to large pits in the surface and this is often called pitting. During the incubation period negligible wear takes place. Hence fatigue is different from the other wear mechanisms where a more gradual deterioration of the surface is observed.

\section{Adhesive Wear}

If the adhesion forces in a sliding contact are high, shear takes place in the weakest material instead of at the surface interface. This may result in detachment of fragments of one surface and attachment to the other surface. At continued sliding material will be transferred across the contact.

Starting from a condition characterised by one or a combination of the other three wear mechanisms, transition to adhesive wear may take place under certain operating conditions. If boundary layers will not hold up by thermal and/or mechanical means metal-metal contact will occur. First (at increasing normal force and/or sliding velocity) material transfer will take place at a microscopic scale. This condition is called incipient scuffing. At even more extreme conditions (even higher normal force and/or higher velocity) very severe adhesive wear will occur. This condition is commonly referred to as scuffing.

\subsubsection{Wear and Failure in the Belt-Pulley Contact}

Under operating conditions in the micro slip regime, mild tribochemical wear, abrasive wear and wear due to fatigue play a role in the element-pulley contact of the push belt. This situation may be regarded as a "relatively mild wear" operating region. Then when in the macro slip region excessive slip occurs, a transition may take place and this may lead to severe wear according to the adhesive wear mechanism. The severe wear may lead to malfunction of the variator (decreased torque capacity as failure mode), as is explained in Section 2.3. Note again that the transition from micro to macro slip does not have to coincide with the transition from mild to adhesive wear.

The elements in the push belt are of the same order of hardness as the pulleys and therefore this will not lead to abrasive wear. However, it is possible that particles generated due to fatigue, running-in or foreign particles cause abrasive wear in the belt-pulley contact.
Fatigue/pitting may occur in the belt-pulley contact, but together with abrasive and tribochemical wear it is not directly related to phenomena that play a role during the transition described above. In other words when the transition is about to happen the initial state of the surface may be affected by one of the milder wear mechanisms and may be worn, but they do not directly lead to a departure from the safe operating region.

At the moment the consensus is that the transition to severe/adhesive wear must be prevented at all times. Very short slip events in the adhesive wear region will cause a deterioration of the torque capacity whereas experience shows that the torque capacity does not change under the assumed safe operating conditions in the micro slip regime. An indication that this also holds for the safe region in the macro slip regime is given in Section 5.2.1.

Diagrams dealing with the transitions in wear regimes and especially diagrams that cover the transition from mild to severe wear are described in the next section.

\subsection{FAILURE DIAGRAMS}

The Stribeck curve usually maps (lubrication) regimes by means of the coefficient of friction as a function of operating conditions under mild wear conditions.

To map failure modes (e.g. transition to adhesive wear) as a function of operating conditions, another diagram is needed. In literature these are known as transition, wear or failure diagrams. For example, see the diagrams by Ashby and Lim [14], PV diagrams [12] and IRG diagrams [11,14-17]. All these diagrams have in common that wear mechanisms, characterised by several criteria, are mapped as a function of a set of operational parameters.

The transitions in dominant wear mechanisms occur as sliding loads and velocities are changed. In some cases, changes also occur as a function of sliding time (or distance). The dominant wear mechanisms are based on mechanical strength and interfacial adhesion. Increase in normal load results in an increase in mechanical damage due to high surface stresses. Increase in both normal load and sliding velocity results in an increase in interface temperature. High interface temperature results in formation or breakdown of chemical films (boundary layers) at the contact interface. Furthermore high temperatures may result in a decrease in mechanical strength and in some cases structural changes. At very high temperatures very severe adhesive wear will take place. 
Possible criteria for determining failure diagrams:

- Change in friction level

- Critical contact/flash temperature

- Failure analysis; wear measurement

In this paper, the IRG-OECD ${ }^{1}$ transition diagram will be adopted. Failure is mapped with regard to normal force $F_{N}$ and sliding velocity $v$ and therefore this diagram is also called the $\mathrm{F} / \mathrm{v}$-failure diagram. This corresponds closely to the variator situation: clamping force and slip. The F/v-failure diagram distinguishes between regions of efficient (mild wear) and inefficient (adhesive wear) performance in non-conforming lubricated sliding contacts [11,14-17]. The failure criterion used is based on the change of friction level in a certain lubricated concentrated contact

For the element-pulley contact this is a useful criterion (cf. Figures 2.3, 2.4 and 4.1), whereas criteria only based on direct wear measurements (e.g. wear volume and/or wear rate $k$ values [18]) are difficult to derive because of the complex nature of the contacting bodies especially the geometry of the element flank, and in-situ wear evaluation is even more difficult to perform.

An example of the F/v-failure diagram is shown in Figure 2.8. In this diagram, where the so-called load-carrying capacity $F_{N}$ is presented as a function of the sliding velocity $v$, three regions, separated by two transition curves, can be distinguished. These regions are governed by the measured friction time characteristics seen in Figure 2.9.

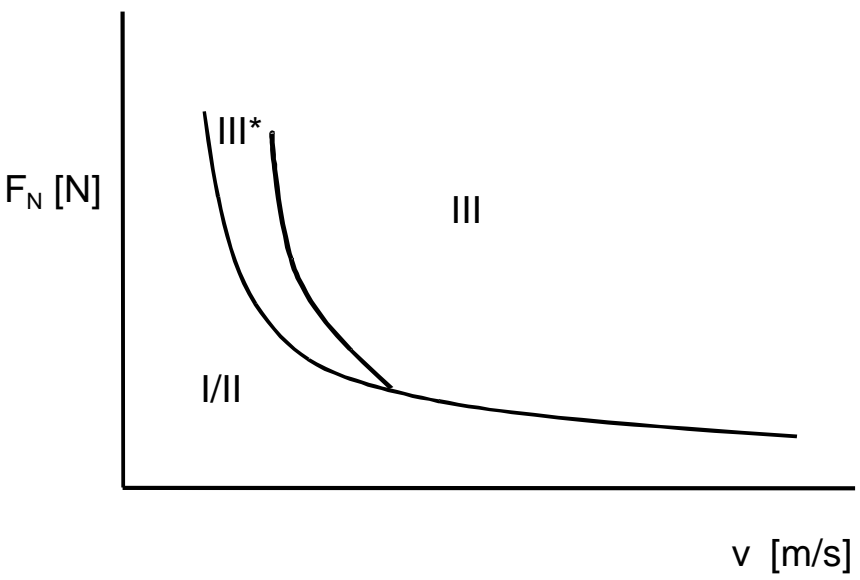

Figure 2.8 Transition diagram or F/v-failure diagram (reproduced from [11]).

\footnotetext{
${ }^{1}$ International Research Group on Wear of Engineering Materials
}

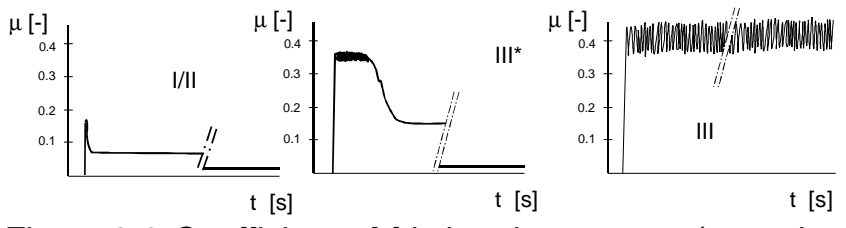

Figure 2.9 Coefficient of friction-time curves (reproduced from [11].

Region $\mathrm{I} / \mathrm{Il}$ is considered to be a mild wear or 'safe' region, where friction is relatively low ( $\mu=0.15$ or less) and wear is virtually negligible (wear rate $k \approx 10^{-8}$ $\mathrm{mm}^{3} / \mathrm{Nm}$ ). The lubricating conditions in this region are $\mathrm{BL}, \mathrm{ML}$ and $\mathrm{EHL}$. In region $\mathrm{II}^{*}$ there is incipient scuffing: material transfer takes place at a microscopic scale and the average contact pressure $\left(p_{a v}\right)$ decreases. In this region, initial values of $\mu \approx 0.35$ and $k \approx 5 \cdot 10^{-6} \mathrm{~mm}^{3} / \mathrm{Nm}$ occur, both decreasing with time. If the contact is to operate in region III, it fails almost immediately by scuffing, with $\mu \approx 0.4$ and $k \approx 10^{-3} \mathrm{~mm}^{3} / \mathrm{Nm}$. In this region very severe adhesive wear (material transfer) will take place.

In the next chapters the F/v-failure diagram for the variator is determined based on measurements.

\section{DETERMINATION OF VARIATOR F/V- FAILURE DIAGRAM}

To determine the variator $\mathrm{F} / \mathrm{v}$-failure diagram, it is necessary to be able to calculate the slip speed and normal force levels in the contact of belt element and pulley sheave. A method is described in Section 3.1. Furthermore, a procedure needs to be developed to control the variator slip speed and normal force in a predetermined manner. This procedure is described in Section 3.2. In Section 3.3 the measurement program is presented.

\subsection{DETERMINATION OF SLIP SPEED AND NORMAL FORCE}

\subsubsection{Determination of Slip Speed $v$}

In the micro slip regime, it is very common to express the variator slip by comparing the variator speed ratio to the no-load or geometrical ratio $i_{o}$ (see Eq.(1)). For the occurrence of adhesive wear, however, the absolute slip speed in $\mathrm{m} / \mathrm{s}$ is of importance.

The absolute element/pulley slip speed $v$ is calculated from the primary and secondary running radii $\left(r_{p}\right.$ and $\left.r_{s}\right)$ and primary and secondary rotational speeds $\left(\omega_{p}\right.$ and $\left.\omega_{s}\right)$ according to: 
$v=\omega_{p} r_{p}-\omega_{s} r_{s}$

Since the measurements were performed with the variator running against its LOW or OD stop, for the primary and secondary running radii $\left(r_{p}\right.$ and $\left.r_{s}\right)$ the theoretical running radii from the geometrical calculations are used (see Table 2.1). Note that this means that all the differences between the no-load ratio and the speed ratio are translated into slip speed. This also includes ratio change caused by pulley defection and belt elongation. In the macro slip regime this causes an offset to the actual slip speed of around $0.1-0.2 \mathrm{~m} / \mathrm{s}(1-2 \%$ in slip rate).

The relation between relative slip rate $s_{r}$ and absolute slip speed $v$ depends on rotational speed and geometrical ratio and is expressed by:

$s_{r}=\frac{v}{\omega_{s} r_{s}} \cdot 100 \%$

\subsubsection{Determination of Normal Force $F_{N}$}

The normal force in the element/pulley contact depends directly on the pulley clamping force applied by hydraulic pressure. This force is distributed over all the elements in the wrapped angle of the pulley. For the determination of the $\mathrm{F} / \mathrm{v}$-failure diagram of the variator, in principle the element that carries the maximum load is most critical.

For reasons of simplicity it is decided to assume that the applied clamping force is distributed equally over all elements in the wrapped angle. As a result, $F_{N}$ can be expressed as a function of geometrical ratio and secondary clamping force only.

$F_{N}=c F_{a x, s}$

The constant $c$ is determined by the number of elements in the wrapped angle of the pulley with the highest slip and (in LOW) the pulley clamping force ratio $\left(F_{a x, p} / F_{a x, s}\right)$. Table 3.1 shows the value of $c$ for geometrical ratio LOW, TOP and OD.

Table 3.1 Part of the secondary clamping force carried by a single element in the wrapped angle.

\begin{tabular}{|l|l|l|l|}
\hline$i_{0}[-]$ & LOW & TOP & OD \\
\hline \hline$c[-]$ & 0.0174 & 0.0134 & 0.0176 \\
\hline
\end{tabular}

\subsection{CONTROL OF SLIP SPEED AND NORMAL FORCE}

The measurements were performed on a variator testrig. For the construction of the F/v-failure diagram it was decided to control $F_{N}$ at a constant level and to vary slip speed $v$ according to a predetermined trajectory. In Figure 3.1 a schematical view of the test-rig is shown.

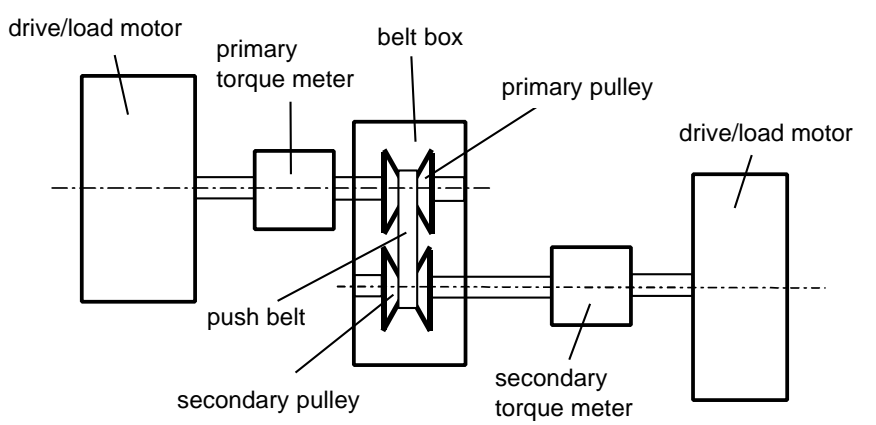

Figure 3.1 Schematic view of the test-rig.

\subsubsection{Control of Normal Force $F_{N}$}

Since $F_{N}$ only depends on the secondary clamping force and the geometrical ratio (see Eq.(5)), $F_{N}$ was controlled by controlling the secondary and primary pressure at a constant level. The secondary pressure level was chosen based on the desired $F_{N}$ level for the desired geometrical ratio. The primary pressure level was chosen in a way that the pulley clamping force ratio $\left(F_{a x, p} / F_{a x, s}\right)$ guaranteed that the variator remained at the OD or LOW stop.

\subsubsection{Control of Slip Speed $v$}

The variator slip speed depends on no-load ratio and primary and secondary rotational speed (see Eq.(3)). In order to be able to accurately control the variator slip speed, the variator was driven by an engine on both sides. This means that instead of the standard setting, which is primary speed and secondary torque control (used for slip curve measurement, see Section 2.2), the primary speed and secondary speed were controlled. Since the clamping pressures were chosen in a way that the geometrical ratio remained constant, the variator slip could be accurately controlled.

All belts were exposed to one or more macro slip events. Figure 3.2 shows the slip profile that was used. 
Three phases can be distinguished:

1. Speed up: 0 to $5 \mathrm{~s}$. The variator starts at very low speed, both the primary and the secondary speed are increased until the target primary speed is reached. During this period, the secondary speed is chosen such that a small positive macro slip is created, causing the torque to be at its maximum positive level corresponding to the applied clamping force and actual coefficient of friction.

2. Large macro slip: 5 to $9 \mathrm{~s}$. When the target primary speed is reached, the secondary speed is decreased for $2 \mathrm{~s}$ linear in time until the target maximum slip speed is reached. After that, the secondary speed is increased in $2 \mathrm{~s}$ to the level corresponding to small positive macro slip.

3. Slow down: 9 to $13 \mathrm{~s}$. Both the primary and secondary speed is decreased to zero. Again a small positive macro slip is maintained.
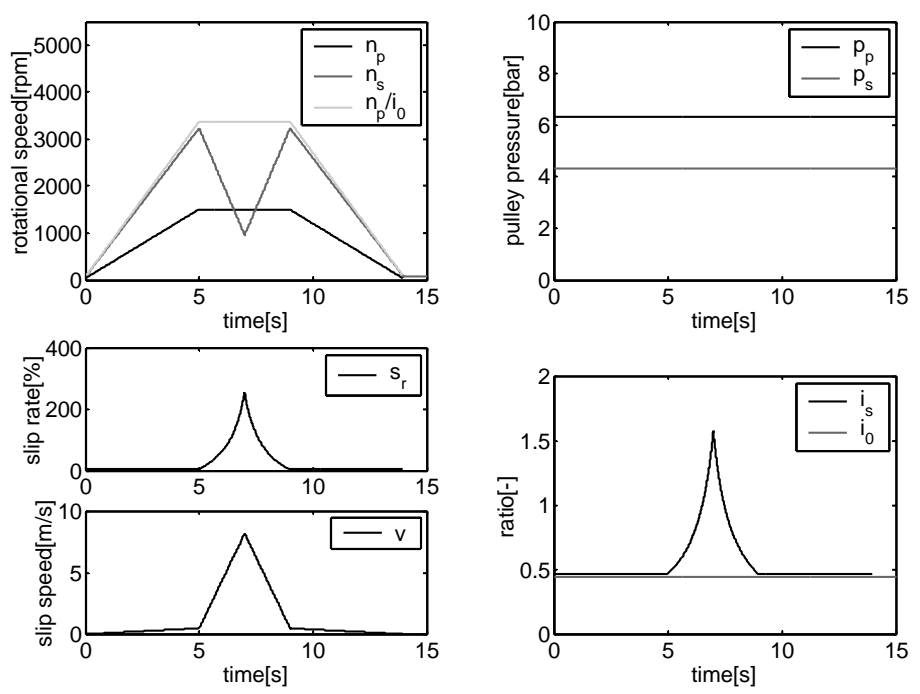

Figure 3.2 Example macro slip event in OD in course of time: setpoints of rotational speeds and setpoints for pulley pressures, the resulting speed ratio and slip level.

\subsubsection{Measurement Example}

Figure 3.3 shows an example of the measurement according to the setpoints shown in Figure 3.2. It is clear that the desired macro slip profile with slip speed levels up to $8 \mathrm{~m} / \mathrm{s}$, corresponding to a slip rate of $300 \%$ can be accurately controlled with the proposed measurement method.

Note that the variator torque levels are now a result of the combination of applied clamping force and slip speed. If the slip changes size or direction (positive to negative), the torque will do the same. Since positive macro slip is controlled, the torque is at its positive slip limit all the time. When the macro slip level increases (between 5 and $7 \mathrm{~s}$ ), the torque decreases, indicating a decrease in coefficient of friction $\mu$ with increased slip speed.
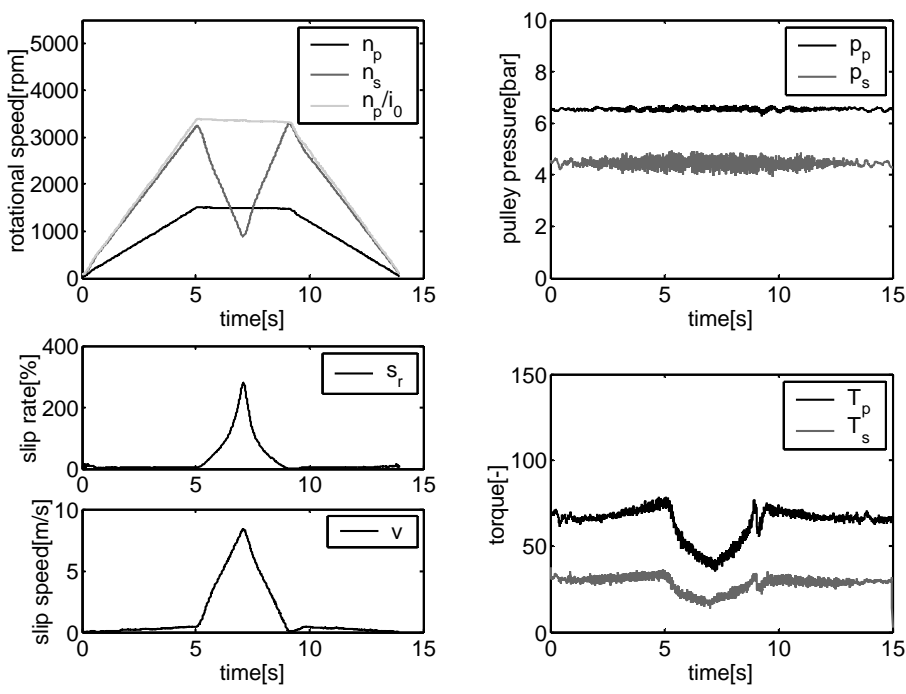

Figure 3.3 Measured macro slip event.

\subsection{MEASUREMENT PROGRAM}

The specification of the variator that was used for the measurements is described in Table 2.1. Since the purpose of the tests was determining the occurrence of adhesive wear, new hardware was used for each test. For each point in the failure diagram a new belt and pulley were used. A running-in procedure at micro slip level was used prior to the macro slip events.

The parameters that were varied were:

- geometrical ratio

- primary rotational speed

- clamping force level

Table 3.2 shows the parameter settings for each belt number.

Table 3.2 Measurement program.

\begin{tabular}{|l|l|l|l|l|}
\hline belt number & $i_{0}[-]$ & $n_{\rho}[\mathrm{rpm}]$ & $p_{S}[\mathrm{bar}]$ & $F_{N}[\mathrm{~N}]$ \\
\hline \hline 1 & LOW & 1500 & 9.4 & 170 \\
\hline 2 & OD & 1500 & 8.6 & 165 \\
\hline 3 & LOW & 1500 & 37.4 & 610 \\
\hline 4 & OD & 1500 & 17.1 & 310 \\
\hline 5 & LOW & 2200 & 2.3 & 60 \\
\hline 6 & OD & 1500 & 2.1 & 55 \\
\hline 7 & LOW & 4000 & 9.4 & 170 \\
\hline 8 & LOW & 4000 & 37.4 & 600 \\
\hline 9 & OD & 1800 & 8.6 & 165 \\
\hline 10 & LOW & 1500 & 18.7 & 330 \\
\hline 11 & OD & 1500 & 4.3 & 90 \\
\hline
\end{tabular}




\section{VARIATOR F/V-DIAGRAM MEASUREMENT RESULTS}

\subsection{DETERMINATION OF THE ADHESIVE WEAR FAILURE LIMIT.}

Similar to the theory described in Section 2.5, the adhesive wear transition is primarily detected by looking at the torque signals (or coefficient of friction) over the course of time. Since the clamping force levels are approximately constant during the test, a sudden increase in torque is associated with increased torque transmittance caused by adhesive wear. This is especially clear when looking at the calculated coefficient of friction during the test.

Figure 4.1 shows the torque signal and calculated coefficient of friction during two different tests. The top shows the torque, slip speed and coefficient of friction for a slip event in OD that did not cause adhesive wear. The bottom shows the same signals for a measurement that did cause adhesive wear. The arrow indicates the start of the adhesive wear. The measurements are from the same belt and were performed right after each other. For the second measurement the maximum slip speed level was increased as compared to the first one (8.3 vs. 9.7 $\mathrm{m} / \mathrm{s})$.

\subsection{THE VARIATOR F/V-FAILURE DIAGRAM}

For each parameter setting the slip speed at the point of failure was determined (the slip speed corresponding to the arrow in Figure 4.1) and displayed in an F/v-failure diagram.

Figure 4.2 shows the variator failure diagram for a selection of measurements:

- $\quad$ all at a primary speed of 1500 rpm except test no.5, which was at a primary speed of $2200 \mathrm{rpm}$,

- in two different ratios (LOW and OD),

- $\quad$ and at different normal force levels.

For test no.5 a higher failure limit than the indicated slip speed is valid, because the belt did not fail at this slip speed, but the slip speed could not be increased because the secondary pulley speed had reached zero.

Note that the F/v-failure diagrams presented in this paper are valid for the used hardware, lubrication fluid type and running-in procedure.

\subsubsection{The Influence of the Variator Ratio}

When the measurements at the same element normal force level and in different ratios are compared (LOW vs. $\mathrm{OD})$, the LOW measurement always fails earlier in terms of slip speed level compared to OD. The difference between the failure point in LOW and OD are 2 to $5 \mathrm{~m} / \mathrm{s}$ depending on the normal force level.
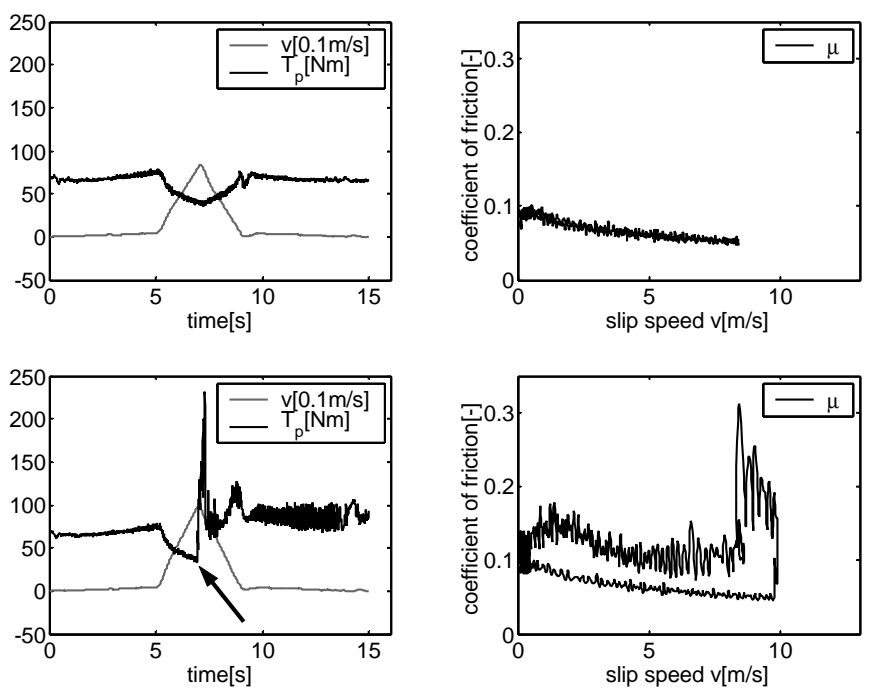

Figure 4.1 Above, the torque, slip speed and coefficient of friction for a slip event in $O D$ that did not cause adhesive wear. Below, the same signals for a measurement that did cause adhesive wear.

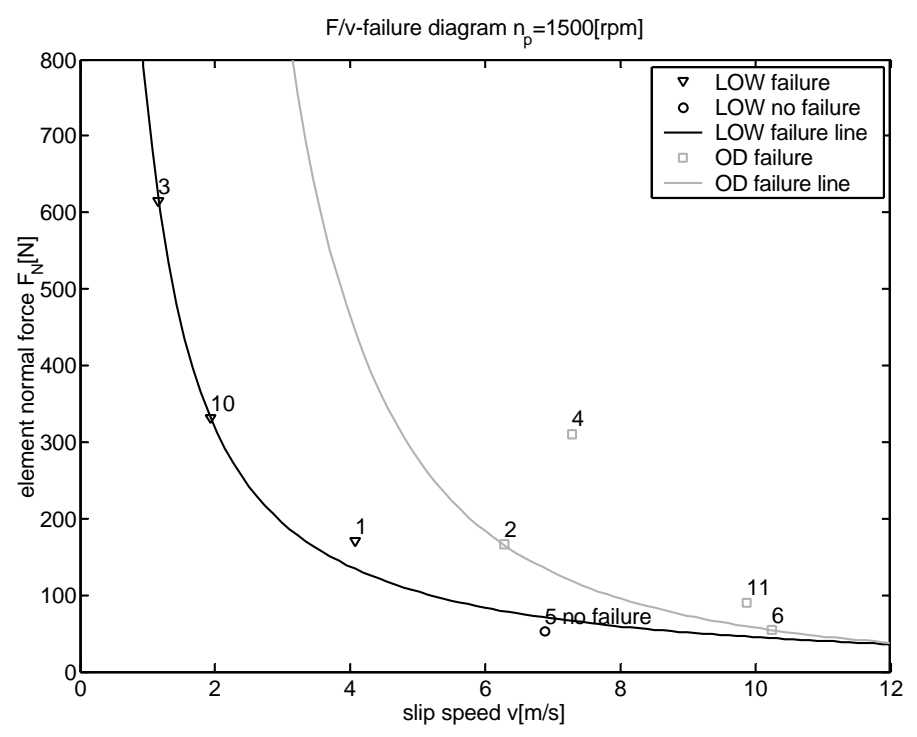

Figure 4.2 F/v-failure diagram measured at a primary speed of $1500 \mathrm{rpm}$.

\subsubsection{The Influence of the Clamping Force Level}

As is expected based on theory (see Section 2.5) the higher the normal force the smaller the failure limit slip speed. In LOW the adhesive wear starts at a slip speed of $1.2 \mathrm{~m} / \mathrm{s}$ at $610 \mathrm{~N}$ maximum element normal force (corresponding to $p_{s}=37$ bar, no.3) whereas at $170 \mathrm{~N}, 4.1$ 
$\mathrm{m} / \mathrm{s}$ is the failure limit (corresponding to $p_{s}=9.4$ bar, no. 1 ) and at $60 \mathrm{~N}$ the belt did not even fail at $6.9 \mathrm{~m} / \mathrm{s}$ (corresponding to $p_{s}=2.3$ bar, no.5). In OD this is less clear because the failures of belt no.2 and no.4 are inconsistent.

\subsubsection{The Influence of the Primary Rotational Speed}

Figure 4.3 shows in LOW at 170 and $600 \mathrm{~N}$ the differences between the adhesive wear limit for a primary speed of 1500 and $4000 \mathrm{rpm}$ and in OD at $165 \mathrm{~N}$ the differences between the adhesive wear limit for a primary speed of 1500 and $1800 \mathrm{rpm}$. In all cases, increasing the primary speed increases the slip speed at which adhesive wear occurs.

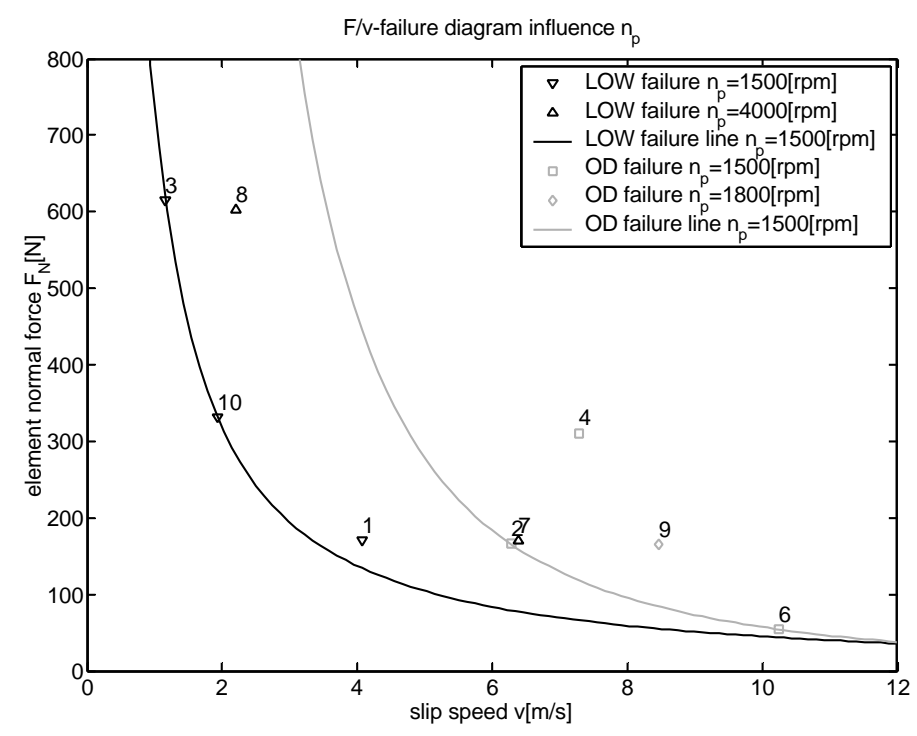

Figure $4.3 \mathrm{~F} / \mathrm{V}$-failure diagram. The influence of the primary rotational speed.

\section{DISCUSSION}

\subsection{THE VARIATOR F/V-FAILURE DIAGRAM AND FAILURE DIAGRAM THEORY}

In this section the F/v-failure diagram that resulted from the variator measurements will be compared with the $\mathrm{F} / \mathrm{v}$-failure diagram from literature. It is possible to judge the transition from a mild wear regime to a severe, adhesive wear regime for the variator by the coefficient of friction signal as well (cf. Figures 2.9 and 4.1). Furthermore, it can be seen that the failure line shows similar trends as a function of the normal force and the slip speed (cf. Figures 2.8 and 4.2/4.3).
However, the transition from wear region $\mathrm{II}^{*}$ (incipient adhesive wear/scuffing region) to region III (adhesive wear/scuffing) could not be distinguished during the variator measurements based on the friction signals. The failure line as shown in Figures 4.2 and 4.3 represents therefore the transition from I/II to $\mathrm{III}^{*}$ or III. Both wear regions $\mathrm{II}^{*}$ and $\mathrm{III}$ are adhesive wear regions and are therefore unacceptable. A possible explanation is that the measurement procedures that are used are different with regard to the amount of time the contact endures the maximum slip value. As can be seen in Figures 3.2 and 3.3 the slip speed decreases directly after reaching a maximum value whereas the procedure as used in literature uses constant slip speed. The time is probably too short to see whether the contact (or coefficient of friction) is recuperating to a milder wear regime due to a decrease contact pressure $\left(\mathrm{III}^{\star}\right)$ or if it continues to scuff (III).

As can be seen in Figures 4.2 and 4.3 there is no unique failure line, but different failure lines for different ratios and rotational speeds are observed. This reveals the need to take into account more factors than only normal force and sliding speed. In contrast to the situation described in Section 2.5, in the variator there is not a permanent contact between belt element and pulley. The contact duration for a single element depends on ratio, rotational speed and slip speed. This might explain why the failure limit is more critical for LOW compared to OD. In LOW the belt slips at the primary pulley. At this pulley, the belt speed is much lower (following the decreasing secondary pulley speed) than the pulley speed. In OD the belt slips at the secondary pulley. In this case, the belt speed is high (slightly less than primary pulley speed) as compared to the secondary pulley speed. This means that the time spent inside the wrapped angle of the slipping pulley is much longer for a slip event in LOW than for a slip event in OD. Table 5.1 shows the estimated time an element spends at the slipping arc for test number 1 and 2 . The slip time in LOW is a factor 18 times the slip time in OD.

Table 5.1 Indication of the time an element spends in the wrapped pulley angle of the slipping side of the variator. Influence of geometrical ratio.

\begin{tabular}{|l||c|c|}
\hline geometrical ratio & LOW & OD \\
\hline \hline $\begin{array}{l}\text { wrapped pulley angle at the } \\
\text { slipping side [m] }\end{array}$ & 0.0783 & 0.0854 \\
\hline belt speed [m/s] & 0.580 & 11.4 \\
\hline slip time per element [s] & 0.135 & 0.00752 \\
\hline $\begin{array}{l}\text { slip time relative to slip time } \\
\text { in OD [-] }\end{array}$ & 18 & 1 \\
\hline
\end{tabular}




\subsection{APPLICATION OF THE VARIATOR F/V-FAILURE DIAGRAM IN CONTROL DEVELOPMENT}

The knowledge of the variator $\mathrm{F} / \mathrm{v}$-failure diagram can be applied for two purposes during variator control development. First, it can be used as a powerful tool to analyse measurements that caused adhesive wear or for situations that, because of the occurrence of macro slip, show a risk of adhesive wear. Secondly, it can be used directly in the clamping force control strategy in a vehicle in order to improve fuel consumption and maximise robustness at the same time. This will be explained in the next paragraphs.

\subsubsection{The Use of the F/v-Failure Diagram for Adhesive Wear Analysis.}

During CVT-clamping force control development and CVT-testing, situations arise in which adhesive wear is detected. To investigate the causes and develop solutions, the F/v-diagram is a powerful tool for analysis.

To illustrate this, the slip curve measurements described in Section 2.3 are displayed in the F/v-failure diagram of Figure 5.3. Although the settings are different from the settings used for the determination of the failure lines (ratio TOP instead of OD and a primary speed op 6000 rpm instead of $1500 \mathrm{rpm}$ ) the failure is very well predicted by the OD-failure line in the $\mathrm{F} / \mathrm{v}$-failure diagram. Measurement no.1 to 22 are in the 'adhesive wear safe' area. Measurement no.23, which is the first measurement that showed adhesive wear, is at the ODfailure line.

The power of the F/v-diagram theory is also shown by another experiment. A six-hour macro slip durability test was performed in OD. The variator was exposed to a macro slip level of $6 \mathrm{~m} / \mathrm{s}$ corresponding to a slip rate of $386 \%$. The test settings are displayed in Table 5.2. Note that the no-load ratio for this test was 0.45 while the speed ratio was around 2.2, which is almost equal to the LOW ratio. Figure 5.3 shows the test setting in the F/vdiagram. Since this point is in the safe area, no adhesive wear occurred during this durability test.

Table 5.2 Test settings of 6 hour lasting high macro slip durability test in $O D$.

\begin{tabular}{|l|l|l|l|l|l|l|}
\hline $\begin{array}{l}n_{p} \\
{[\mathrm{rpm}]}\end{array}$ & $\begin{array}{l}n_{s} \\
{[\mathrm{rpm}]}\end{array}$ & $\begin{array}{l}v \\
{[\mathrm{~m} / \mathrm{s}]}\end{array}$ & $\begin{array}{l}\mathrm{S}_{\mathrm{r}} \\
{[\%]}\end{array}$ & $\begin{array}{l}p_{s} \\
{[\mathrm{bar}]}\end{array}$ & $\begin{array}{l}F_{N} \\
{[\mathrm{~N}]}\end{array}$ & $\begin{array}{l}T_{p} \\
{[\mathrm{Nm}]}\end{array}$ \\
\hline \hline 1006 & 461 & 6 & 386 & 3.3 & 60 & 36 \\
\hline
\end{tabular}

Note that the fact that there was no adhesive wear in the element/pulley contact does not imply that the degree of the other forms of mild wear discussed in Section 2.4.1 (tribochemical wear, abrasive wear and fatigue) will not increase when running for a long time under safe operating conditions with respect to adhesive wear. The $\mathrm{F} / \mathrm{V}$-failure diagram is used for the prediction of adhesive wear only.

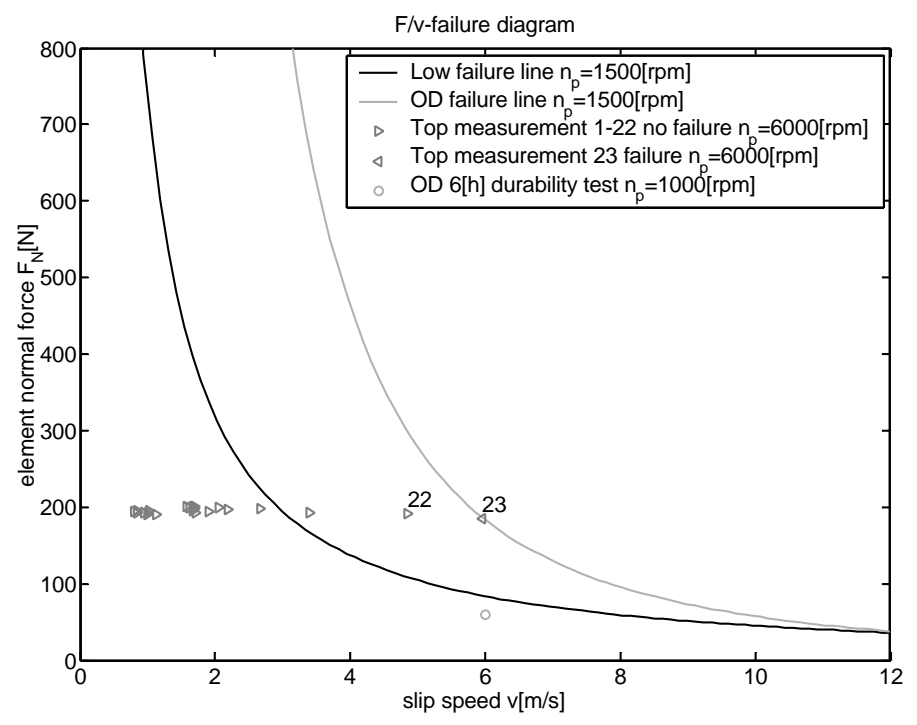

Figure 5.3 The slip curve measurements described in Section 2.3 and the high macro slip durability test setting displayed in the F/v-failure diagram.

\subsubsection{New Control Strategies Based on the F/v-Failure Diagram}

Current control strategies attempt to prevent macro slip between elements and pulleys at all times for maximum robustness. The investigation described in this paper shows that, with respect to adhesive wear, macro slip can be allowed, as long as the failure lines in the F/vfailure diagram are not exceeded.

This new insight opens up the possibility of the development of clamping force strategies that prevent crossing the failure lines in the F/v-failure diagram instead of preventing macro slip at all times. In practice this will lead to lower variator clamping forces under all operating conditions. As already explained in the introduction this is one of the conditions for the realisation of improved fuel consumption and increased power density.

Note that strategies that control macro slip in stationary situations are not desired because of the fact that optimum efficiency is reached under micro slip conditions. With increasing macro slip, CVT-efficiency decreases sharply. The benefit of the F/v-diagram knowledge is that in stationary situations lower clamping 
forces can be applied because in case of unexpected torque peaks or pressure dips:

1. The safety margin for the occurrence of adhesive wear is larger than assumed until now, especially in OD and in part load situations

2. The F/v-diagram makes it possible to react in a safe manner with respect to adhesive wear when macro slip is detected.

Some examples of direct application of the F/v-failure diagram knowledge in the clamping force control strategy are:

- Direct slip control or slip monitoring possibly in combination with functionality that realises:

1. a limitation of the clamping pressure based on a measured slip signal and/or

2. a limitation of the slip based on a measured clamping force level.

- Clamping force control that adapts the control parameters on-line when macro slip is detected.

Control development at VDT is aimed at realising these strategies in order to realise the potential fuel consuption decrease up to $5 \%$.

\section{CONCLUSION}

The main conclusion of this paper is that the presented F/v-failure diagram can be used to optimise the variator control strategy by applying lower clamping forces in order to realise improved fuel consumption (up to 5\%) and power density without compromising robustness for adhesive wear.

\section{Furthermore it can be concluded that:}

- The occurrence of adhesive wear leads to a decrease in variator torque capacity and must therefore be regarded as a variator failure mode.

- Adhesive wear in the belt/pulley contact is caused by a combination of a too high slip speed and clamping force level.

- By controlling both primary and secondary speed at a known geometrical ratio, it is possible to control a desired macro slip profile in time.

- With respect to adhesive wear, macro slip is acceptable to a certain extent. The allowed macro slip rate depends on the operating conditions. Examples shown in this paper are:

1. In TOP at a primary speed of $6000 \mathrm{rpm}$ and a secondary pressure of 9.9 bar a slip rate of $13 \%$ is allowed.

2. In OD at a primary speed of $1000 \mathrm{rpm}$ and a secondary pressure of 3.3 bar, a slip rate of $386 \%$ is allowed.
- A first estimation of the failure limit for the variator is determined by measurements and displayed by a failure line in the F/v-failure diagram.

- In general the relation between normal force and slip speed that describes the adhesive wear failure limit of the variator is similar to the theory.

- Besides slip speed and clamping force, the measurements show that the occurrence of wear also depends on the geometrical ratio (LOW more critical than OD) and the primary speed (the lower the more critical).

\section{REFERENCES}

1. Brandsma, A., van Lith, J., Hendriks, E., "Push belt CVT developments for high power applications", Proc. of CVT99, Eindhoven University of Technology 1999, pp.142-147.

2. Van der Sluis, F., Brandsma, A., van Lith, J., van der Meer, K., van der Velde, A., Pennings, B., "Stress reduction in push belt rings using residual stresses", Proc. of CVT2002 Congress, VDI-Berichte 1709, Munich, October 2002, pp.383-402.

3. Van Spijk, G., Veenhuizen, B., "An upshift in CVTefficiency", Proc. of Getriebe in Fahrzeugen '98. VDIBerichte 1393, Friedrichshafen, June 1998, pp.659671.

4. Van der Sluis, F., et al., The two-stage push belt CVT, IIR symposium Offenbach Germany 2002

5. Van der Sluis, F, "A New Pump for CVT Applications", SAE 2003-01-3207, Proc. of the 2003 Powertrain \& Fluid Systems Conference, Pittsburgh, October 2003.

6. Van der Laan, M., Luh, J., "Model-Based Variator Control Applied to a Belt Type CVT", Proc. of CVT99, Eindhoven University of Technology 1999, pp.105-116.

7. Pennings, B., Drogen, M. van, Brandsma, A., Ginkel, E. van, Lemmens, M., "Van Doorne CVT Fluid Test A Test Method on Belt-Pulley Level to Select Fluids for Push Belt CVT Application", SAE 2003-01-3253, Proc. of the 2003 Powertrain \& Fluid Systems Conference, Pittsburgh, October 2003.

8. Kobayashi, D., Mabuchi, Y. and Katoh, Y., "A Study on the Torque Capacity of a Metal Pushing V-belt for CVTs", SAE Paper 980822, 1998.

9. DIN 50320: Verschleiß - Begriffe, Systemanalyse von Verschleißvorgängen, Gliederung des Versleißgebietes, Beuth Verlag, Berlin, 1979.

10. Schipper, D.J., "Transition in the Lubrication of Concentrated Contacts", Ph.D. thesis, University of Twente, 1988. 
11. Schipper, D.J. and Gee, A.W.J. de, "Lubrication Modes and the IRG Transition Diagram", Lubrication Science 8-1, 1995, pp. 27-35.

12. Bhushan, B., "Principles and Applications of Tribology", Wiley, New York, 1999.

13. Landheer, D. and Gee, A.W.J. de, "Tribologie - deel A: Inleiding dynamische contactverschijnselen", Lecture notes, University of Twente, The Netherlands, 1994.

14. Czichos, H., "Presentation of Friction and Wear Data", ASM Handbook, Vol. 18, 1992, pp. 489-492.

15. Begelinger, A. and Gee, A.W.J. de, "Failure of Thin Film Lubrication - The Effect of Running-In on the Load Carrying Capacity of Thin Film Lubricated Concentrated Contacts", Journal of Lubrication Technology, Vol. 103, 1981, pp. 203-210.

16. Gee, A.W.J. de and Begelinger, A., "Failure mechanisms in sliding lubricated concentrated contacts", Proceedings of the $11^{\text {th }}$ Leeds-Lyon Symposium on Mixed Lubrication and Lubricated Wear, 1984.

17. Schipper, D.J., Steenmeijer, R.C. and Gee, A.W.J. de, "The Effects of Variations in the Procedure of Loading on the Load Carrying Capacity of Thin Film Lubricated Concentrated Contacts", Proceedings of the $4^{\text {th }}$ International Tribology Conference, Austrib94, Vol. I, 1994, pp. 105-112, ISBN 064621097
18. DIN 50321: Verschleißmeßgrößen, Beuth Verlag, Berlin, 1979.

\section{DEFINITIONS}

c: element normal force constant [-]

$i_{0}$ : no-load speed ratio [-]

$i_{s}:$ speed ratio $[-]$

$k$ : wear rate $\left[\mathrm{mm}^{3} / \mathrm{Nm}\right]$

$n_{p}$ : primary rotational speed [rpm]

$n_{s}$ : secondary rotational speed $[\mathrm{rpm}]$

$p_{p}$ : primary pressure [bar]

$p_{s}$ : secondary pressure [bar]

$r_{p}$ : primary running radius $[\mathrm{m}]$

$r_{s}$ : secondary running radius $[\mathrm{m}]$

$s_{r}$ : slip rate [\%]

$v$ : slip speed $[\mathrm{m} / \mathrm{s}]$

$F_{\text {ax, }}:$ primary clamping force $[\mathrm{N}]$

$F_{a x, s}$ : secondary clamping force $[\mathrm{N}]$

$F_{N}$ : normal force $[\mathrm{N}]$

$T_{p}$ : primary torque $[\mathrm{Nm}]$

$T_{s}$ : secondary torque $[\mathrm{Nm}]$

$\lambda$ : pulley angle [rad]

$\mu$ : coefficient of friction [-]

$\omega_{p}$ : primary rotational speed [rad/s]

$\omega_{s}:$ secondary rotational speed $[\mathrm{rad} / \mathrm{s}]$ 